\title{
Online Ortamda Reklama Yönelik Tutum, Gösteriş Tüketimi ve Alışveriş Bağımlılığı İlişkilerinin İncelenmesi \\ (Investigation of Relationships Among Attitudes Towards Advertising, Conspicuous Consumption and Shopping Addiction in Online Environment)
}

\section{İbrahim BOZACI iD a Şaban ALTIN iD b İsmail GÖKDENIZ iD c}

a Kırıkkale Üniversitesi, Keskin Meslek Yüksekokulu, Pazarlama, Kırıkkale, Türkiye. iborganizer@gmail.com

b Bozok Üniversitesi, Sosyal Bilimler Meslek Yüksekokulu, Büro Hizmetleri ve Sekreterlik, Yozgat, Türkiye. sabanaltin0797@gmail.com

c Kırıkkale Üniversitesi, İktisadi ve İdari Bilimler Fakültesi, İşletme, Kırıkale, Türkiye. isgokdeniz@gmail.com

\begin{tabular}{|c|c|}
\hline MAKALE BİLGİSİ & ÖZET \\
\hline $\begin{array}{l}\text { Anahtar Kelimeler: } \\
\text { Online Reklam } \\
\text { Reklama Yönelik Tutum } \\
\text { Bağımlılık } \\
\text { Alışveriş }\end{array}$ & $\begin{array}{l}\text { Amaç - İnternet erişiminin artması, internet kullanımının yaygınlaşması ve insanların zamanının } \\
\text { önemli kısmını internet üzerinde geçirmesi, internet üzerinde sorunlu veya bağımlılık düzeyinde } \\
\text { tüketici davranışlarının ortaya çıkmasına neden olmaktadır. Davranışsal bağımlılık türlerinin } \\
\text { günümüzün önemli ve yönetilmesi zor sorunlarından biri olduğundan hareketle gerçekleştirilen bu } \\
\text { araştırmada, online alışveriş bağımlılığı ve bunu etkilemesi olası faktörleri ortaya koymak } \\
\text { amaçlanmaktadır. }\end{array}$ \\
\hline Gönderilme Tarihi 19 Mart & $\begin{array}{l}\text { Yöntem - Kırıkkale ilinde kolayda örnekleme yöntemiyle gerçekleştirilen anket çalışmasıyla birincil } \\
\text { veriler toplanmış ve elde edilen veriler analiz edilmiştir. Verilerin analizinde değişkenlerin yapısal } \\
\text { geçerliliğine yönelik doğrulayıcı faktör analizi ve araştırma hipotezlerinin test edilmesine yönelik } \\
\text { yapısal eşitlik modelinden yararlanılmıştır. }\end{array}$ \\
\hline $\begin{array}{l}2020 \\
\text { Revizyon Tarihi } 18 \text { Mayıs } 2020 \\
\text { Kabul Tarihi } 22 \text { Mayıs } 2020\end{array}$ & $\begin{array}{l}\text { Bulgular - Araştırma sonuçlarına göre online reklama yönelik olumlu tutumun, online gösteriş } \\
\text { tüketimini ve online alışveriş bağımlılığını pozitif yönde etkilediği fikri desteklenmiştir. Ayrıca } \\
\text { online prestij tüketiminin, online reklama yönelik tutumun online bağımlılık üzerindeki etkisinde } \\
\text { kısmi aracılık rolü üstlendiği tespit edilmiştir. }\end{array}$ \\
\hline $\begin{array}{l}\text { Makale Kategorisi: } \\
\text { Araştırma Makalesi }\end{array}$ & $\begin{array}{l}\text { Tartışma - Tüketicinin online ortamdaki reklamlara yönelik tutumlarının, online ortamdaki } \\
\text { alışveriş bağımlllığını ve online gösteriş tüketimini etkilediği şeklinde varılan sonuç, geleneksel } \\
\text { alışverişlere yönelik gerçekleştirilen araştırmalarla benzerdir. Dolayısıyla online reklamlara yönelik } \\
\text { tutumun, araştırmada incelenen değişkenler başta olmak üzere, online ortamda tüketici } \\
\text { davranışlarını etkileyen bir değişken olduğu anlaşlmaktadır. }\end{array}$ \\
\hline ARTICLE INFO & ABSTRACT \\
\hline $\begin{array}{l}\text { Keywords: } \\
\text { Online Advertisement } \\
\text { Attitude toward Advertising } \\
\text { Addiction }\end{array}$ & $\begin{array}{l}\text { Purpose - Increased internet access, widespread use of internet, and people spending most of their } \\
\text { time on the internet cause the emergence of problematic or addictive consumer behavior on the } \\
\text { internet. As behavioral addiction types are one of the important and difficult to manage problems } \\
\text { of today, in this research, it is aimed to reveal the online shopping addiction and the possible factors } \\
\text { that may affect it. }\end{array}$ \\
\hline $\begin{array}{l}\text { Shopping } \\
\text { Conspicuous Consumption }\end{array}$ & $\begin{array}{l}\text { Design/methodology/approach - In the Kirikkale province, the primary data was collected and the } \\
\text { data obtained were analyzed by a survey conducted with convenience sampling method. In the } \\
\text { analysis of the data, a structural equation model was used for testing hypotheses and confirmatory } \\
\text { factor analysis was used for the structural validity of the variables. }\end{array}$ \\
\hline $\begin{array}{l}\text { Revised } 18 \text { May } 2020 \\
\text { Accepted } 22 \text { May } 2020\end{array}$ & $\begin{array}{l}\text { Findings - According to the research results, the idea that positive attitude towards online } \\
\text { advertising affects online conspicuous consumption and online shopping addiction positively. In } \\
\text { addition, it has been determined that online conspicuous consumption plays a partial mediating role } \\
\text { in the effect of attitude towards online advertising on online addiction. }\end{array}$ \\
\hline $\begin{array}{l}\text { Article Classification: } \\
\text { Research Article }\end{array}$ & $\begin{array}{l}\text { Discussion - The conclusion reached is that the attitudes of the consumers towards the } \\
\text { advertisements in the online environment affect the shopping addiction in the online environment } \\
\text { and the online conspicuous consumption similar to the researches conducted for the traditional } \\
\text { shopping. Therefore, it is understood that the attitude towards online advertising is a variable that } \\
\text { affects consumer behavior in the online environment, especially the variables examined in the } \\
\text { research. }\end{array}$ \\
\hline
\end{tabular}

\section{Önerilen Atıf/ Suggested Citation}

Bozacı, İ., Altın, Ş., Gökdeniz, İ.(2020). Online Ortamda Reklama Yönelik Tutum, Gösteriş Tüketimi Ve Alışveriş Bağımlılığı İlişkilerinin İncelenmesi, İşletme Araştırmaları Dergisi, 12 (2), 1447-1458. 


\section{GIRISS}

İnsanların uzun süredir madde bağımlılığıyla mücadele etmesi, madde bağımlılığının belirgin şekilde sorun olarak kabul edilmesi ve tıp ve psikiyatri bilimlerindeki gelişmeler sayesinde madde bağımlılığının önlenmesi ve tedavisinde başarılar elde edilebilmektedir. Ancak teknolojik gelişmelere bağlı olarak bağımlılık türleri çeşitlenmiştir. İnternet bağımlılığı gibi tespit edilmesi daha zor olan davranışsal bağımlılık türlerinin sosyal ve mesleki olarak insanları olumsuz etkilediği bilinmektedir (Ertemel ve Aydın, 2018). Bunlar arasında yer alan internet bağımlı̆̆ dünya çapında önemli bir sorun olarak kabul görmüştür (Bozkurt vd., 2016). Türkiye'de de internet kullanımı hızla artmaktadır. Örneğin Türkiye İstatistik Kurumu Bilgi Toplumu İstatistikleri'ne göre; hanelerde internet erişimi 2007 ile 2019 yılları arasında sürekli arttı̆̆ı ve bu oranın 2007'de \% 19,7 iken, 2019'da \% 88,3 olduğu görülmektedir (http://www.tuik.gov.tr/PreTablo.do?alt_id=1028). İnternet kullanımının hayatın her düzeyinde artması, internetle ilgili bağımlılıkların yaygınlaşmasıyla ilişkilidir (Balcı ve Gülnar, 2009; Günüç ve Kayri, 2010; Gökçearslan ve Günbatar, 2012; Füsun ve Ümmet, 2013; Y1lmaz vd., 2014).

Alışverişlerin her ne kadar genellikle müşteriler için normal ve rutin davranış olmasına karşın, bazı müşteriler için kontrol edilemeyen veya takıntılı bir sürece dönüşebildiği bilinmektedir (O'Guinn ve Faber, 1989; McElroy vd., 1994). Örneğin bir araştırmaya göre ABD'de alışveriş bağımlığının \% 6 civarında olduğu tahmin edilmektedir (Müller ve Mitchell, 2014). Alışveriş bağımlılığı veya zorlayıcı satın alma davranışları geleneksel mağaza ortamında artmasının yanında, online alışveriş ortamlarında da artmaktadır (Dittmar, 2005). Geleneksel dağıtım kanalları bakımından dikkat çeken alışveriş bağımlılığının internet ortamında da olmasına karşın, bu bakımdan gerçekleştirilen çalışmaların az sayıda olduğu görülmektedir. Bir alışveriş kanalı olarak internet, müşteriye istediği zaman istediği yerde alışveriş yapmasına imkan vermesi, müşterilerin kolayca erişebilmesi ve işletmelerin bu iletişim kanalında müşterileri etkileyen uygulamalara (çekici sunumlar, kampanyalar vb.) başvurması gibi nedenlerle (Sharma vd., 2010), zorlayıcı alışverişin bu bakımdan incelenmesi önemlidir (Kukar-Kinney vd., 2009; Müller ve Mitchell, 2014).

Genç tüketicilerle gerçekleştirilen bir araştırma sonuçlarına göre, online alışveriş bağımlılığının \% 16 ve internet bağımlılı̆̆ının \% 26 oranında yaygın olduğu tespit edilmiştir. Buna göre, online alışveriş bağımlıları; online alışveriş̧ sitelerine sık sık erişmekte, bağımlı olmayanlara göre daha fazla para ve zaman harcamaktadır (Duroy vd., 2014). Kısaca internet kullanımının yaygınlaşması, internette kalınan sürenin artması ve internete daha sık bağlanmaya bağlı olarak, online alışveriş bağımlılık haline dönüşebilmektedir (Lejoyeux vd., 2007). $\mathrm{Bu}$ araştırmada internet aracılığıyla alışverişlerde kontrolün kaybolması ve buna bağlı sorunlar yaşama gibi boyutlardan oluştuğu ifade edilen "online alışveriş bağımlılı̆ıı"nın nedenlerine dikkat çekilmekte ve güncel bir bağımlılık türünü anlamaya katkı sağlamak amaçlanmaktadır.

\section{KAVRAMSAL ÇERÇEVE VE HIPOTEZ GELIŞTIIRME}

Alışveriş bağımlılı̆̆ı, klinik araştırmacılar tarafından yaygınlıkla incelenmekle birlikte, pazarlama veya tüketici araştırmacılarının da ilgisini çekmektedir (Kukar-Kinney vd., 2012). İhtiyaç duyulmasa da ürünleri satın almaya yönelik tekrarlayan ve kontrol edilemeyen dürtüler olarak açıklanan alışveriş bağımlılığı veya zorlayıcı satın alma; alışverişin bireyde strese, zaman kaybına, sosyal, mesleki ve finansal zorluklara neden olmasına ve kontrol edilemeyen satın alma davranışları göstermesine göre belirlenmektedir (McElroy vd., 1994).

Zorlayıcı elektronik satın alma veya online alışveriş bağımlılığı ise, bireyler saplantılı şekilde olumsuz ruh hallerini düzeltmek gibi nedenlerle online ortamda alışveriş yapmasına bağlı olarak ortaya çıan bir sorun olarak ifade edilmektedir (Wang ve Yang, 2008; Lee ve Park, 2008). Online zorlayıcı alışveriş; üzerinde az sayıda araştırma yapılmış, kontrol ve güdülerin kaybına dayalı olarak ve finansal ve zaman bakımından tüketiciye olumsuz etkileri olan bir davranış bozukluğudur (Duroy vd., 2014).

Online alışveriş bağımlılığını etkileyen faktörler bakımından, öncelikle bireysel nedenler üzerinde durulmaktadır. LaRose ve Eastin'in (2002) çalışmasında, olumsuz ruh hali ve zayıf öz düzenlemenin kontrolsüz online satın alma eğilimini artırdığı tespit edilmiştir. Lee vd.'nin (2016) araştırmasında ise benlik saygısı ve internet bağımlılığı online zorlayıcı satın almayı etkileyen faktörler olarak tespit edilmiştir. İlgili çalışmada ayrıca offline zorlayıcı satın alma ve internet bağımlılığı ile online zorlayıcı internetten satın alma 


\section{İ. Bozac1 - Ş. Altın - İ. Gökdeniz 12/2 (2020) 1447-1458}

arasında olumlu ve güçlü ilişkiler tespit edilmiştir. Dolayısıyla düşük benlik saygısına sahip olma ve internet bağımlısı olmanın, online alışveriş bağımlısı olmaya neden olan faktörler arasında olduğu anlaşılmaktadır.

Online alışverişin kolaylığı ve internette normatif standartların azlığı, online zorlayıcı satın almaya neden olabilmektedir. Lee ve Park'ın (2008) çalışması, normatif uymanın (seçim yaparken sanal topluluktakilere danışma vb.) elektronik zorlayıcı satın almayı negatif yönde etkilediğini göstermektedir. Bu nedenle zorlayıcı satın almayı engellemede tüketicilere sosyal normları hatırlatma ve sanal topluluklara dikkat çekme önerilmektedir. İlgili çalışmada ulaşılan sonuç, normatif uyumun zorlayıcı satın almayı olumsuz etkilediğini gösteren Lee vd.'nin (2000) araştırma sonuçlarıyla benzerdir.

Online alışveriş bağımlılığının, bireysel faktörlerin yanında, reklam gibi iletişimler başta olmak üzere işletme faaliyetlerinden de etkilenmesi mümkündür. Reklamın tüketicilere etkilerine yönelik pazarlama biliminde çok sayıda araştırma gerçekleştirilmiştir. Özellikle reklamın; tüketicilerin dürtülerini harekete geçirdiğini (Moore ve Lee, 2012), satın almaya teşvik ettiğini, satın alma isteği uyandırdığını (Pechman vd., 2005; Hudders vd., 2016), marka sermayesi oluşturduğunu (Anantachart, 2006), davranışta bulunmayı teşvik ettiğini (Griffiths ve Wood, 2001) araştırmalar göstermektedir. Bunların yanında reklamların tüketicileri, işletmeler karşısında daha savunmasız hale getirebildiği (Baker vd., 2005; Melnikas ve Smaliukiene, 2007), bağımlıklara (kumar vb.) neden olabildiği (Felsher vd., 2004) ve zorlayıcı alışverişleri artırabildiği de araştırmalarda görülmektedir (Guo ve Cai, 2011; Sohn ve Choi, 2012).

Bu noktada reklamların marka tutumu ve satın alma niyeti gibi tüketiciler üzerinde etkilerinin oluşmasında reklama yönelik tutumlar önemli rol oynayabilmektedir (Ferle ve Lee, 2003; Tan ve Chia, 2007; Defever vd., 2011; Lee vd., 2016). Dolayısıyla tüketicinin belirli reklam uyarıcısına verdiği olumlu veya olumsuz tepki eğilimi olarak tanımlanan reklama yönelik tutumun (MacKenzie vd., 1986), tüketicinin satın alma kararları (Durmuş ve Battal, 2018) ve zorlayıcı satın almayla ilişkili olması söz konusudur (D'Astous, 1990).

Reklamın tüketicilerin satın alma isteği üzerindeki etkisi; reklamın satış niyetini anlama (Lapierre, 2019) ve reklam okuryazarlığı (Vanwesenbeeck vd., 2017) gibi faktörlerin yanında genel düzeyde veya belirli reklam türüne (internet reklamları vb.) yönelik tutumlardan etkilenebilmektedir (De Jans vd., 2018). Reklama yönelik olumsuz tutumların temel sonucu, reklamdan kaçınmadır (Prendergast vd., 2010; Kim ve Seo, 2017). Bu durum internet ortamında reklam engelleyici yazılım kullanma gibi davranışlar şeklinde ortaya çıkabilmektedir (Redondo ve Aznar, 2018). Eroğlu'nun (2016) Türkiye'de gerçekleştirdiği araştırması da, reklama yönelik tutumun, kompulsif satın almayı etkilediğini göstermiştir.

Genel düzeyde reklamların tüketici satın alma eğilimi ve bağımlılığına etkilerine ilişkin araştırmaların yanında Duro vd.'nin (2014) çalışmasında; anlık olumlu duygular yaşama ve seçeneğin fazla olduğu kapsamlı tekliflerin online alışverişleri etkilediği sonucuna varılmıştır. Ayrıca web sitelerinde günlük sunulan tekliflere ilişkin pazarlama iletişimleri, müşteride zaman baskısı ve diğer müşterilerle arasında sosyal gerilim veya yarışma ortamı yaratabilmektedir (Kukar-Kinney vd., 2016).

Reklam tutumlarının reklamın tüketicilere etkilerini azaltabildiğine yönelik bilimsel literatür göz önünde bulundurulduğunda, online reklama yönelik tutumları olumsuz olan tüketicilerin bu gibi reklamlardan etkilenme düzeyinin daha az olması beklenebilir. Bu açılamalara bağlı olarak araştırmanın birinci hipotezi ileri sürülmektedir:

$\mathrm{H}_{1}$ : Online reklamlara yönelik tutum, online alışveriş bağımlılığını etkilemektedir.

Online reklamlara yönelik tutumların, online alışveriş bağımlılı̆̆ının yanında, online gösteriş tüketimini de etkilemesi mümkündür. Gösteriş tüketimi, insanların kişisel amaçlarına ulaşmasının diğerlerine bağlı olması ve insan işlevselliğinin diğerlerinin kendileri hakkındaki düşüncelerinden etkilenmesi varsayımına dayanır. İnsandaki başarı veya sosyal konumun gösterilmesi içgüdüsü (Chaudhuri vd., 2011), insanların varlıklar aracılığıyla kendilerini diğerlerine açıklamasına (Bahn vd., 1982; Byrne, 1990; Hız, 2011), tüketim davranışlarında diğerlerinin arzu ve tepkilerini göz önünde bulundurmasına veya kısaca gösteriş tüketimine neden olmaktadır (Belk, 1988).

İşletmeler de ürünün fiyatından çok, sağladığı prestij değerine vurgu yaparak tüketicileri etkilemeye çalışabilmektedir. Örneğin işletmeler tutundurma faaliyetlerinde ürünleri kullananları; zengin, diğerlerini etkileyen, çekici ve gıpta edilen insanlar olarak tanıtabilmektedir (Thrift, 2008). Dolayısıyla reklamın tüketimin 


\section{İ. Bozac1 - Ş. Altın - İ. Gökdeniz 12/2 (2020) 1447-1458}

artmasında ve gösteriş tüketiminin teşvik edilmesinde önemli bir araç olduğu kabul görmektedir (Kocak, 2017). Bu noktada, reklamlara yönelik tutumların, insanların materyalizm anlayışını (Yoon, 1995) ve gösteriş tüketim eğilimini etkilemesinde (Khoshghadam vd., 2018) olduğu gibi, online reklama yönelik tutumların, online gösteriş tüketimini etkilemesinin mümkün olduğu düşünülmekte ve araştırmanın ikinci hipotezi ileri sürülmektedir:

$\mathrm{H}_{2}$ : Online reklamlara yönelik tutumlar, online gösteriş tüketimini etkilemektedir.

Araştırma kapsamında, online gösteriş tüketiminin online alışveriş bağımlılı̆̆ını etkileyebileceği fikri tartışılmaktadır. Kimliğini ürünleri satın alarak geliştirmek isteyenlerin, zorlayıcı alışverişe karşı daha savunmasız olduğunu gösteren araştırma sonuçlarıyla karşılaşılmaktadır (Dittmar, 2005). Eroğlu'nun (2016) Türkiye'de gerçekleştirdiği araştırması da, gösterişçi tüketimin kompulsif satın almayı etkilediğini göstermiştir. Benzer şekilde Dittmar vd.'nin (2007) çalışmasında, online ortamda duygularını (eğlenme, daha iyi hissetme, haz alma vb.) ve kimliğini desteklemek (olmak istediği birey gibi hissettiren, diğerlerini etkileyen, prestij sağlayan) isteyen bireylerde, zorlayıcı online satın alma eğiliminin daha yüksek olduğu tespit edilmiştir. Bu açıklamalara bağlı olarak, izleyen araştırma hipotezi ileri sürülmektedir:

$\mathrm{H}_{3}$ : Online prestij tüketimi, online alışveriş bağımlığını etkilemektedir.

Araştırmada online reklamlara yönelik tutumun, online alışveriş bağımlılı̆̆ına etkisinde online prestij tüketiminin aracı rolü test edilmekte veya online reklamlara yönelik tutumun online prestij tüketimi aracılığıyla online alışveriş tüketimi üzerindeki olası etkisi sorgulanmaktadır. Buna göre araştırmanın dördüncü hipotezi oluşturulmaktadır.

$\mathrm{H}_{4}$ : Online prestij tüketimi, online reklama yönelik tutumun online alışveriş bağımlılığı üzerindeki etkisine aracılık etmektedir.

Özetle literatürde incelediğimiz araştırmalara dayalı olarak bu çalışmada teorik açıdan varılan sonuçlar; online ortamda karşılaşılan reklamlara yönelik tutumun, online prestij tüketimini ve online alışveriş bağımlılı̆̆ını etkilediği, online prestij tüketiminin online alışveriş bağımlılığını etkilediği ve online reklama yönelik tutumun online alışveriş bağımlılı̆̆ı üzerinde aracılık rolü üstlenebileceğidir. Araştırmanın uygulama kısmına ise bu iddialar birincil verilerle test edilmektedir.

\section{YÖNTEM}

\subsection{Araştırmanın Amacı ve Modeli}

Bu araştırmanın temel amacı, online alışveriş bağımlılı̆̆ında, online reklama yönelik tutumlar ve online prestij tüketiminin rolünü ortaya koymaktır. Böylece bağımlılık türü olarak ifade edilen sorunlu bir tüketici davranışının nedenlerine dikkat çekilmektedir. Ayrıca online gösteriş tüketiminin, online reklama yönelik tutumun online alışveriş bağımlılığı üzerindeki etkisindeki aracılık rolü incelenmektedir. Araştırma modeli, Şekil 1.'de görülmektedir.

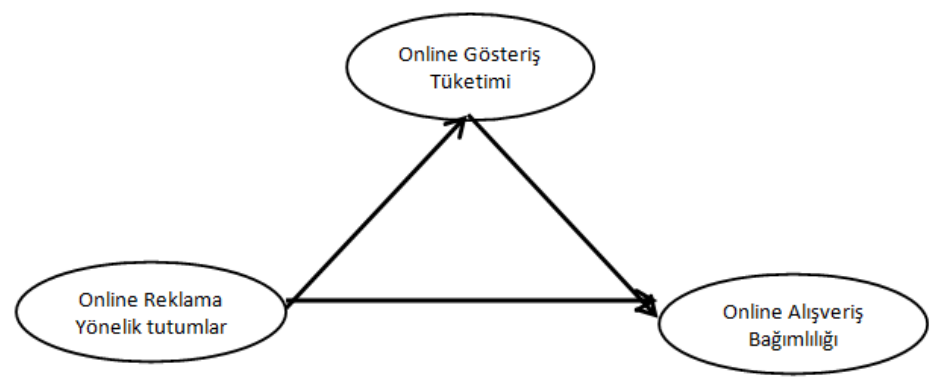

Şekil 1: Araştırma Modeli

\subsection{Evren, Örneklem ve Verilerin Toplanması}

Araştırma evreni Kırıkkale ili merkezinde internet üzerinden alışveriş yapan tüketiciler olarak belirlenmiştir. Araştırma modelinin test edilmesi doğrultusunda, öncelikle örneklem çerçevesi bilgisine erişme imkanı olmadığından, kolayda örnekleme yöntemiyle birincil veriler toplanmıştır. Bu yöntem, her ne kadar tesadüfi örnekleme yöntemlerine göre zayıf nitelikte veri toplamaya imkan sağlasa da, sosyal bilimlerde hipotezlere 


\section{İ. Bozac1 - Ş. Altın - İ. Gökdeniz 12/2 (2020) 1447-1458}

ilişkin kanıtların üretilmesinde yaygınlıkla kullanılmaktadır. Bu bağlamda Kırıkkale ilinde 10.8.2019-10.9.2019 tarihleri arasında kaynak kısıtlarından dolayı 309 tüketiciden birincil veriler toplanmıştır. Örnekleme yöntemi ve örneklem hacmi her ne kadar araştırma evrenine yönelik genelleştirmeye imkan vermese de, araştırma hipotezlerini test etmede yeterli olarak değerlendirilmiş ve analizler gerçekleştirilmiştir.

Araştırma değişkenlerinin ölçülmesinde pazarlama literatüründe yer alan ölçüm araçlarından uyarlama yoluna gidilmiştir. Değişkenler 5'li Likert formatında (1. Kesinlikle Katılmıyorum, 5. Kesinlikle Katılıyorum) hazırlanmıştır. Buna göre online reklamlara yönelik genel tutumu ölçmek üzere Wolin vd. (2002) ve Başaran vd.'nin (2017) reklam tutumlarını ölçmede kullandığı ifadeler araştırmaya uyarlanmıştır. Online prestij tüketimi değişkenini ölçmek için ise Dittmar vd. (2007), Chung ve Fisher (2001), Segal ve Podoshen (2013) ve Podoshen vd.'nin (2014) araştırmalarından yararlanılmıştır. Bunların yanında online alışveriş bağımlığı değişkenini ölçmek üzere Faber (1992), Lee ve Park (2008) ve Andreassen vd.'nin (2015) araştırmalarından uyarlama yoluna gidilmiştir.

\section{BULGULAR}

\subsection{Katılımcıların Genel Özellikleri}

Araştırmaya katılanların cinsiyet bakımından \% 52,4'ünün erkek, \% 46,3'ünün kadın olduğu görülmektedir. Yaş bakımından ise katılımcıların \% 54,4'ünün 35 ve altı yaş aralığında olduğu, aylık gelir bakımından ise katılımcıların \% 45,6'sının 2.101-3600 TL arasında gelire sahip olduğu anlaşılmaktadır.

Tablo 1. Demografik Özelliklere İlişkin Bulgular

\begin{tabular}{|c|c|c|c|c|c|}
\hline Yaş & $\mathbf{n}$ & $\%$ & Aylık gelir & $\mathbf{n}$ & $\%$ \\
\hline $20-27$ & 79 & 25,6 & 0-2100TL & 81 & 26,2 \\
\hline $28-35$ & 89 & 28,8 & 2101-3600TL & 141 & 45,6 \\
\hline $36-43$ & 94 & 30,4 & 3601 TL ve üstü & 82 & 26,4 \\
\hline 44 ve üstü & 45 & 14,5 & Toplam & 304 & 98,3 \\
\hline Toplam & 307 & 99,3 & & & \\
\hline \multicolumn{6}{|l|}{ Cinsiyet } \\
\hline Erkek & 162 & 52,4 & & & \\
\hline Kadın & 143 & 46,3 & & & \\
\hline Toplam & 305 & 98,7 & & & \\
\hline
\end{tabular}

\subsection{Verilerin Normal Dağılımına ve Güvenilirlik Analizlerine İlişkin Bulgular}

Örneklem grubundan elde edilen verilerin normal dağılım varsayımını sağlama durumunu tespit etmek için yaygınlıkla kullanılan basıklık (kurtosis) ve çarpıklık (skewness) değerleri (Tabachnick ve Fidell, 2012:79) incelenmiştir. Bu değerlerin , +/- 1,0 veya +/-1,5 aralığında (Bayram, 2010:49), sig. $<0,01$ olduğunda +/-2,58 olması veya sig $<0,05$ ise $+/-1,96$ aralığında (Hair vd., 2009:72) veya $+/-3$ veya $+/-2$ aralığında olması normal dağılım için yeterli görülebilmektedir (Kalaycı, 2009:6). Tablo 2 de yer alan tanımlayıcı istatistik ve güvenilirlik sonuçlarına göre örneklemden elde edilen "Basıklık (kurtosis) ve Çarpıklık (skewness)" değerlerine ait analiz sonuçlarının +/-2 aralığında yer aldığı ve değişkenlere ait değerlerin normal dağılıma sahip olduğu görülmektedir. Yapılan bu araştırmadaki her bir ölçeğin güvenilirlik analizlerine göre güvenilirlik değerlerinin (Cronbach Alfa değerinin) 0,80-1,00 aralığında olduğu görülmektedir. Bu sonuçlara göre ölçeklerin oldukça güvenilir ölçekler olduğu söylenebilir (Kalayc1, 2009: 405). 
İ. Bozacı - Ş. Altın - İ. Gökdeniz 12/2 (2020) 1447-1458

Tablo 2. Verilerin Dağılımı ve Güvenilirliğine İlişkin Bulgular

\begin{tabular}{|c|c|c|c|c|c|c|}
\hline \multirow[b]{2}{*}{ Ölçekler } & \multirow[t]{2}{*}{ Maddeler } & \multicolumn{2}{|c|}{ Çarpıklık } & \multicolumn{2}{|c|}{ Basıklık } & \\
\hline & & Değer & Std. Hata & Değer & Std. Hata & Alfa \\
\hline \multirow{3}{*}{ Online Reklama Yönelik Tutum } & İnternetreklami1 & , 140 & 139 & $-1,036$ & 276 & \multirow{3}{*}{944} \\
\hline & internetreklami2 & ,138 & 139 &,- 976 & 276 & \\
\hline & internetreklami3 & 260 & ,139 &,- 843 & ,276 & \\
\hline \multirow{3}{*}{ Online Gösteriş Tüketimi } & internetalisveris1 & -658 & ,139 &,- 995 & 276 & \multirow{3}{*}{,956 } \\
\hline & internetalisveris2 &,- 546 & 139 & $-1,143$ & ,276 & \\
\hline & internetalisveris3 &,- 567 & ,139 & $-1,235$ & ,276 & \\
\hline \multirow{13}{*}{ Online alışveriş bağımlığı } & davranis1 & 1,124 & ,139 & ,034 & 278 & \multirow{13}{*}{,973 } \\
\hline & davranis2 & 1,070 & ,139 &,- 051 & 276 & \\
\hline & davranis3 & ,476 & ,139 & $-1,265$ & ,276 & \\
\hline & davranis4 & 1,030 & ,139 &,- 192 & 276 & \\
\hline & davranis5 & ,722 & 139 &,- 934 & ,276 & \\
\hline & davranis6 & 1,336 & 139 &, 580 & ,276 & \\
\hline & davranis7 & ,757 & ,139 &,- 831 & ,276 & \\
\hline & davranis8 & 1,352 & ,139 & ,615 & ,276 & \\
\hline & davranis9 & 1,451 & ,139 & ,838 & ,276 & \\
\hline & davranis10 & 1,387 & ,139 & ,762 & ,276 & \\
\hline & davranis11 & 1,082 & ,139 &,- 144 & ,276 & \\
\hline & davranis12 & 1,488 & ,139 & 1,144 & ,276 & \\
\hline & davranis13 & ,931 & , 139 &,- 410 & ,276 & \\
\hline
\end{tabular}

\subsection{Geçerlilik Analizi ve Hipotezlerin Testi}

Araştırmada yer alan her bir soru grubunun geçerliliği, doğrulayıcı faktör analizi (DFA) ile test edilmiştir. Her bir değişkenin faktör yapıları AMOS 18.0 istatistik programı kullanılarak doğrulanmıştır. Faktör yapılarının analizinde maksimum olabilirlik tahmin yönteminden yararlanılmıştır. YEM'de bu yöntem faktör yapılarının dağılımlarının doğrulanması (Hair vd., 2009: 636; Schumacker ve Lomax, 2010: 85; Bayram, 2010:51) ve araştırma modeline ait uyum iyiliği değerlerinin en iyi sonuçlar vermesi açısından önemlidir.

Ölçeklerden elde edilen verilerin doğrulanması için yapılan DFA sonuçlarına göre, verilerin ölçüm modelleri tarafından doğrulandığı gözlemlenmiştir. Ölçüm modellerinden elde edilen değerlere göre gerekli uyum iyileştirmeleri yapılmış ve standardize edilmiş faktör yükü 0,70'in altında olan (Hair vd., 2009: 679) ifadeler analize dahil edilmemiştir. Buna göre online alışveriş bağımlılı̆̆ı ölçeğinde yer alan 3. ve 13. İfadeler değerlendirmeye alınmamıştır. Ölçüm modellerinin uyumluluğunu değerlendirmede temel göstergelerden

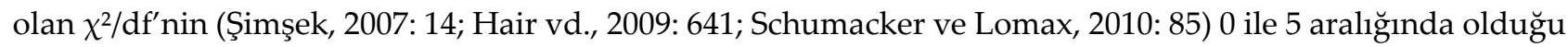
görülmektedir. Ki-kare değeri/serbestlik derecesi $\left(\Delta \chi^{2} / \mathrm{df}=3,557\right)$ değerinin 1-3 aralığında olması mükemmel uyumu, 3-5 aralığında olması ise kabul edilebilir uyumu göstermektedir (Şimşek, 2007:14). Bazı araştırmacılara göre bu değerlerle birlikte RMSEA, GFI, CFI, NFI değerleri de oldukça önemlidir. RMSEA değeri 0,05 ile 0,08 arası kabul edilebilir uyuma, RMR 0,06 ile 0,08 arası iyi uyuma karşılık gelirken, CFI, NFI, GFI değerleri 0,90 ile 0,95 arası kabul edilebilir uyum değerleridir (Meydan ve Şeşen, 2015: 37, Gürbüz, 2019: 34). Bu bakımdan ölçeklerin uyum iyi değerlerinin yeterli olduğu anlaşılmaktadır.

Tablo 3. Doğrulayıcı Faktör Analizi Bulguları

\begin{tabular}{|l|l|l|l|l|l|l|l|l|}
\hline & $\mathbf{p}$ & $\boldsymbol{\Delta} \boldsymbol{\chi}^{2} / \mathbf{d f}$ & $\mathbf{R M S E A}$ & $\mathbf{C F I}$ & $\mathbf{N F I}$ & $\mathbf{G F I}$ & AGFI & RMR \\
\hline Online Reklama Yönelik Tutum &, 000 & 1,987 & 0,087 & 0,845 & 0,835 & 0,796 & 0,743 & 0,042 \\
\hline Online Gösteriş Tüketimi &, 000 & - & 1,03 & 1,000 & 1,000 & 1,000 & 1,000 & 0,000 \\
\hline Online Alışveriş Bağımlılığı &, 000 & 4,216 & 0,102 & 0,970 & 0,961 & 0,907 & 0,846 & 0,043 \\
\hline
\end{tabular}




\section{İ. Bozacı - Ş. Altın - İ. Gökdeniz 12/2 (2020) 1447-1458}

Araştırma modelinin anlamlılığ ve kabul edilebilir olduğuna dair değerler Tablo 4'de gösterilmiştir. Modelin uyum iyiliği değerlerine bakıldığında, değerlerin kabul edilebilir düzeylerde olduğu gözlenmiştir. Bu değerler bakımından da araştırma modelinin kabul edilebilir olduğu anlaşılmaktadır.

Tablo 4. Araştırma Modelinin Uyum İyiliği Değerleri

\begin{tabular}{|l|l|l|l|l|l|l|l|l|l|}
\hline Ölçüm & $\Delta \chi^{2}$ & $\mathbf{P}$ & $\mathbf{d f}$ & $\Delta \chi^{2} / \mathbf{d f}$ & RMSEA & CFI & NFI & GFI & RMR \\
\hline Model & 394,813 &, 000 & 111 & 3,557 & 0,091 & 0,958 & 0,943 & 0,873 & 0,066 \\
\hline
\end{tabular}

Şekil 2'de yer alan araştırma modelindeki değişkenler arasındaki ilişkilere bakıldığında, online reklama yönelik tutumların, online gösteriş tüketimini ve online alışveriş bağımlılı̆̆ını artırdığı, online prestij tüketiminin ise online alışveriş bağımlılığını azalttığı görülmektedir.

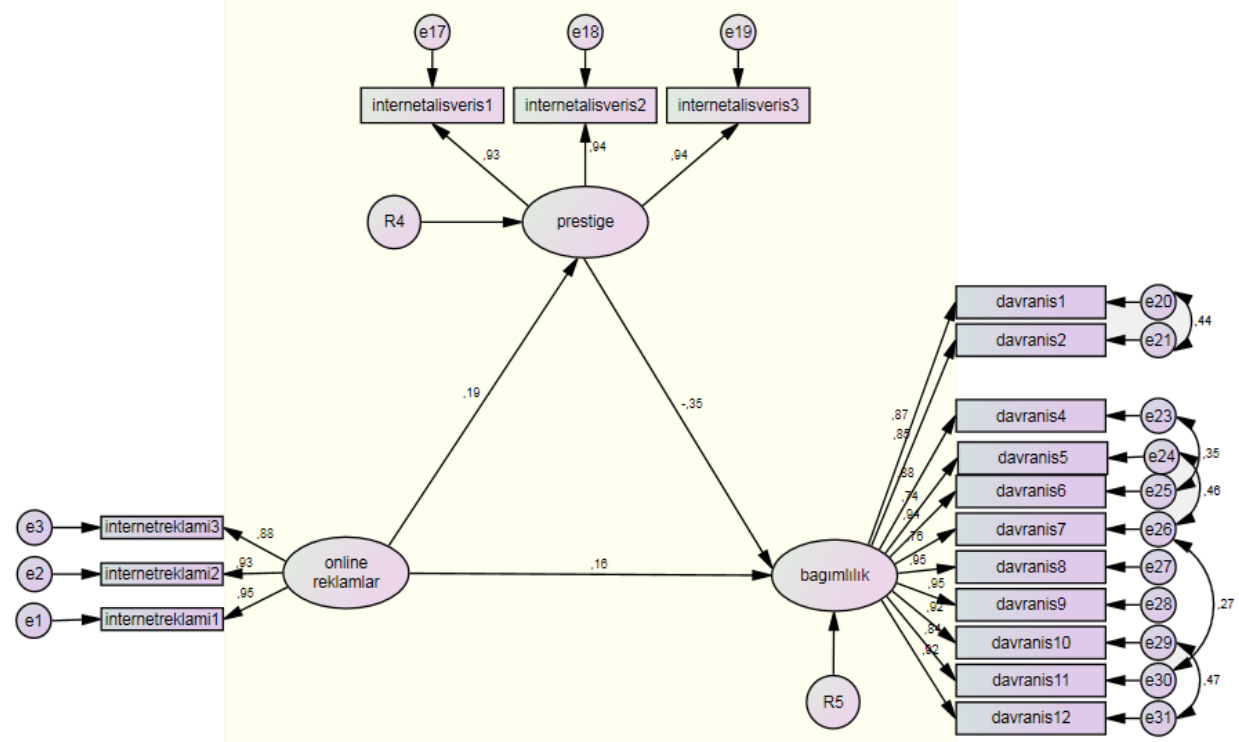

Şekil 2. Araştırma Modeli Bulguları

Tablo 5'de araştırma modeline ait değişkenler arasındaki ilişkilerin standardize edilmiş regresyon katsayıları görülmektedir. Elde edilen bulgulara göre tüm değişkenler arası ilişkiler istatistiksel olarak anlamlıdır. Bu durumda, online reklama yönelik tutum, online alışveriş bağımlılık düzeyini pozitif ve doğrudan etkilemektedir $(\beta=, 16$ ve $p<0,005)$. Dolayısıyla $\mathrm{H}_{1}$ hipotezi kabul edilmektedir. Ayrıca online reklam tutumları, tüketicilerin online gösteriş tüketim düzeyini pozitif ve doğrudan etkilemektedir $(\beta=, 19$ ve $\mathrm{p}<0,002)$. Buna bağlı olarak $\mathrm{H}_{2}$ hipotezi kabul edilmektedir. Bunların yanında online gösteriş tüketiminin, online alışveriş bağımlılık düzeyini olumsuz şekilde ve doğrudan etkilemektedir $(\beta=-, 349$ ve $p<0,000)$. Dolayısıyla $\mathrm{H}_{3}$ kabul edilmektedir.

Tablo 5. Yapısal Eşitlik Modeli Standardize $\beta$ Katsayıları

\begin{tabular}{|l|l|l|l|l|}
\hline Değişkenler Arası İlişkiler & Standardize Edilmiş $\beta$ & $\mathrm{P}$ \\
\hline Online Alışveriş Bağımlılığı & $<---$ & Online Reklama Yönelik Tutum &, 157 & 0,005 \\
\hline Online Gösteriş Tüketimi & $<---$ & Online Reklama Yönelik Tutum &, 186 & 0,002 \\
\hline Online Alışveriş Bağımlılığı & $<---$ & Online Gösteriş Tüketimi &,- 349 & $* * *$ \\
\hline
\end{tabular}

Aracı değişken iki değişken arasındaki ilişkinin anlaşılmasına yardımcı olan değişken olarak ifade edilmektedir (Gürbüz,2019: 106). Aracılık etkisinin olması için; bağımsız değişken, bağımlı ve aracı değişkeni etkilemeli, aracı değişken bağımlı değişkeni etkilemeli ve aracı değişken diğer değişkenlerle birlikte değerlendirildiğinde, bağımsız değişkenin bağımlı değişkene olan etkisi düşmeli ve aracı değişken bağımlı değişkeni etkilemelidir (Baron ve Kenny, 1986; Meydan ve Şeşen, 2015: 130). Araştırma online reklama yönelik tutum olan bağımsız değişkenin, online alışveriş bağımlılığı olarak ifade edilen bağımlı değişkeni etkilediği tespit edilmiştir. İkinci olarak online reklama yönelik tutumun, aracı değişken olan online gösteriş tüketimini de etkilediği görülmektedir. Üçüncü olarak online gösteriş tüketimi değişkeninin, online alışveriş bağımlılığını etkilediği anlaşılmaktadır. Bu durumda aracılık etkisinin ölçülmesinde birinci, ikinci ve üçüncü koşullar sağlanmıştır. 


\section{İ. Bozac1 - Ş. Altın - İ. Gökdeniz 12/2 (2020) 1447-1458}

Değişkenler arasındaki dolaylı etkilere ait standardize edilmiş etki değerlerine bakıldığında; online reklama yönelik tutumun, online alışveriş bağımlılığı değişkeni üzerinde dolaylı etkisi $(\beta=-, 065 \mathrm{p}<0,005)$ görülmektedir. Bu sonuca göre $\mathrm{H}_{4}$ hipotezi kabul edilmiştir. Yani online reklama yönelik tutum değişkeninin, online alışveriş bağımlılığı değişkeni üzerindeki etkisinde online prestij tüketimi değişkenin "kısmi aracılık" etkisi olduğu anlaşılmaktadır.

Online reklama yönelik olumlu tutum düzeyinin, online gösteriş tüketiminin pozitif yönde etkilediği şeklinde varılan sonuç; tüketicinin online reklamları iyi veya gerekli bulması ve bunları beğenmesinin, online ortamda kendisini diğerlerine göstermek ve diğerlerini etkilemek gibi şekillerde ifade edilen online gösteriş tüketiminde daha fazla bulunmasıyla ilişkili olduğunu göstermektedir. Ayrıca online reklamlara yönelik olumlu tutumların; internet üzerinden alışverişleri kontrol edememe, zamanının önemli kısmını internet alışverişleri için düşünme, internet üzerinden alışveriş yapamadığında kendini kötü hissetme, gerektiğinden fazla internet üzerinden alışveriş yapma gibi bileşenlerden meydana gelen online alışveriş bağımlılığını da pozitif yönde etkilediği de göz önünde bulundurulduğunda, online reklama yönelik tutumların incelenen online ortamdaki tüketici davranışlarının her ikisi için de önemli olduğunu ortaya koymaktadır.

Bunların yanında online gösteriş tüketiminin, online alışveriş bağımlılığını ters yönde etkilemesi ve online reklama yönelik tutumların online alışveriş bağımlılı̆̆ üzerindeki etkisinde azaltıcı yönde kısmi aracılık rolü üstlenmesi araştırmada dikkat çeken bir sonuç olmuştur. Zira geleneksel alışveriş ortamlarında prestij tüketiminin, alışveriş bağımlılığını pozitif yönde etkilediğine ve reklam tutumlarının gösteriş tüketimini artırdığına ilişkin değerlendirilen araştırma bulgularının, internet ortamında yön değiştirdiği, ancak gösteriş tüketiminin aracılık etkisinin devam ettiği anlaşılmaktadır. Öyle ki online gösteriş tüketiminin, online alışveriş bağımlılığını ters yönde etkilemesi ve online reklam tutumlarının online gösteriş tüketimi aracılığıyla online alışveriş bağımlılığını azaltıcı dolaylı bir etkisinin olması dikkate değerdir. Bu durumun online gösteriş tüketiminde, geleneksel alışveriş ortamına göre bireyin daha çok araştırma/karşılaştırma imkanlarına sahip olması ve daha kontrollü veya isteğe bağlı satın alma kararları verebilmesinden kaynaklanması mümkündür.

\section{SONUÇ VE TARTIŞMA}

Araştırma sonuçlarına göre online reklama yönelik tutumun, online alışveriş bağımlılığını pozitif ve doğrudan etkilediği görülmektedir. Bu sonuç, tüketicinin reklama yönelik tutumunun, zorlayıcı satın almayı (D'Astous, 1990; Eroğlu, 2016) etkilediğini gösteren araştırma sonuçlarıyla benzerdir. Ancak bu araştırma sonucu, online ortamdaki reklamlara yönelik tutumların, online ortamda gerçekleştirilen alışveriş bağımlılığını etkilediğini göstermesi bakımından özgündür. Buna göre tüketicilerin online reklamlara yönelik olumlu tutumlarının artmasının, online alışveriş bağımlılığını düşük düzey de olsa artırması beklenebilir.

Ayrıca online reklama yönelik tutumların, online gösteriş tüketimini pozitif yönde ve doğrudan etkilediği şeklinde varılan sonuç, reklama yönelik tutumların, insanların gösteriş tüketimiyle yakından ilişkili olan materyalizm anlayışını (Yoon, 1995) ve gösteriş tüketim eğilimini etkilediğini (Khoshghadam vd., 2018) gösteren araştırma sonuçlarıyla benzerlik göstermektedir. Bu durum, reklama yönelik tutum ile gösteriş tüketimi ilişkisinin online alışverişlerde de söz konusu olduğu ve online gösteriş tüketimini teşvik etmede online reklamlara yönelik olumlu tutum oluşturulmasının bir yöntem olarak kullanılabileceği şeklinde yorumlanmaktadır.

Araştırmada ulaşılan online gösteriş tüketiminin online alışveriş bağımlılığını olumsuz etkilediğine yönelik varılan sonuç, geleneksel alışveriş ortamlarında gösteriş amaçlı tüketimin, zorlayıcı alışverişleri pozitif yönde etkilediğini gösteren araştırma (Dittmar, 2005; Dittmar vd., 2007; Eroğlu; 2016) sonuçlarından farklıdır. Araştırmada ulaşılan bu bulgu, gösteriş tüketiminin her durumda alışveriş bağımlılığına neden olmayabileceği ve online ortamda gösteriş tüketimin artmasının, online alışveriş bağımlılığını azaltabileceği şeklinde yorumlanmaktadır. Tüketicilerin internet üzerinde gösteriş tüketiminin geleneksel alışverişlere göre daha bilgiye dayalı olması, daha karşılaştırma yapmaya imkan vermesi gibi özelliklerinden dolayı, alışveriş bağımlılığıyla ilişkili olmayabileceği düşünülmektedir. Aracılık etkisine ilişkin sonuç değerlendirildiğinde, online reklama yönelik tutumun, online alışveriş bağımlılığı değişkeni üzerinde dolaylı veya kısmi aracılık etkisi görülmektedir. Dolayısıyla online reklama yönelik tutumların, online gösteriş tüketimi aracılığıyla online alışveriş bağımlılığını azaltıcı etkiye neden olduğu ancak bu aracılık etkisinin kısmi olduğu anlaşılmaktadır. 


\section{İ. Bozac1 - Ş. Altın - İ. Gökdeniz 12/2 (2020) 1447-1458}

Genel olarak araştırma bulguları özetlendiğinde, online reklama yönelik tutumun, tüketicilerin online gösteriş tüketimi ve online alışveriş bağımlılığı üzerinde pozitif yönde etkisinin olduğu anlaşılmaktadır. Diğer taraftan online gösteriş tüketiminin, online alışveriş bağımlılığı üzerinde azaltıcı bir etkiye sahip olduğu ve online reklama yönelik tutumun bu nedenle online alışveriş bağımlılı̆̆ üzerinde kısmi bir azaltıcı etkiye sahip olduğu anlaşılmaktadır. Bu sonuçlar, online reklama yönelik olumlu tutumların artırılmasının, tüketicilerin online ortamdaki farklı türlerdeki alışveriş davranışlarını pozitif yönde etkileyeceğini göstermektedir.

Araştırma bulgularının, prestijli veya lüks markaları pazarlayan veya prestij odaklı müşterileri hedefleyen işletmeler için ve alışveriş bağımlılığını azaltmayı amaçlayan kamu veya sağlık kuruluşları bakımından yararlı olabileceği düşünülmektedir. Buna göre online reklama yönelik tutumların artırılmasının, prestij tüketimini artırması mümkündür. Diğer taraftan, online reklama yönelik olumlu tutum düzeyinin, online alışveriş bağımlılığını artırması, toplumsal düzeyde karşılaşılan sorunların çözümüne yönelik iletişim stratejilerinde bu faktörün göz önünde bulundurulabileceğini göstermektedir. Bu noktada eğitim ve sağlik kuruluşlarının, online alışveriş bağımlılığının çözümünde, online reklama yönelik olumlu tutumları azaltmasının sorunun çözümüne katkı sağlaması mümkündür.

Araştırmanın başlıca kısıtları olarak anket yöntemiyle gerçekleştirilmesi, dar bir coğrafi alanda gerçekleştirilmesi ve online ortamdaki alışverişlere yönelik gerçekleştirilmesinden kaynaklı ölçüm araçlarında uyarlamalar yapılmasının gerektirmesi olarak ifade edilebilir. Buna göre araştırma sonuçlarının mutlak anlamda doğruluğu ve genelleştirilebilirliği garanti edilememektedir. Ancak incelenen örneklemde, tartışılan tüketici davranışlarını anlama bakımından üretilen bilgilerin yararlı olduğu ve izlenen yöntem bakımından konuyla ilgili gerçekleştirilecek araştırmalara ışık tutma potansiyeli olması bakımından araştırmanın yararlı olduğu düşünülmektedir. Özellikle online alışveriş bağımlılı̆̆ının nedenlerini anlamayı amaçlayan araştırmalarda, online reklama yönelik tutum değişkeninin göz önünde bulundurulmasının ilgili modellerin açıklayıcılığını artırması beklenmektedir.

\section{KAYNAKÇA}

Anantachart, S. (2006). Integrated marketing communications and market planning: Their implications to brand equity building. Journal of Promotion Management, 11(1), 101-125.

Andreassen, C. S., Griffiths, M.D., Pallesen, S., Bilder, R.M., Torsheim, T., ve Aboujaude, E. (2015). The Bergen Shopping Addiction Scale: reliability and validity of a brief screening test. Frontiers in psychology, 6, 111.

Bahn, K., Belk, D., Russell, W. ve Mayer, R.N. (1982). Developmental recognition of consumption symbolism. Journal of Consumer Research, 9(1), 4-17.

Baker, S.M., Gentry, J.W. ve Rittenburg, T. L. (2005). Building Understanding of the Domain of Consumer Vulnerability. Journal of Macromarketing, 25, 128-139.

Balcı, Ş., ve Gülnar, B. (2009). Üniversite öğrencileri arasında internet bağımlılı̆̆ı ve internet bağımlılarının profili, Selçuk İletişim, 6(1), 5-22.

Baron, R. M. ve Kenny, D. A. (1986). The Moderator-Mediator Variable Distinction İn Social Psychological Research: Conceptual, Strategic and Statistical Considerations. Journal of Personality and Social Psychology, 51 (6), 1173-1182.

Başaran Alagöz, S., Yazgan, A. E., ve Baiturova, K. (2017). Tüketicilerin İnternet Bağımlılığının Sosyal Medya Reklamlarına Yönelik Genel Alg1 Ve Tutumları Üzerindeki Etkisi. Journal of Suleyman Demirel University Institute of Social Sciences, 29(4), 287-310.

Bayram, Nuran. (2010), Yapısal Eşittlik Modellemesine Giriş- Amos Uygulamaları. İstanbul: Ezgi Kitapevi.

Belk, R. W. (1988). Possessions and the extended self. Journal of Consumer Research, 15, 139-168.

Bozkurt, H., Şahin, S., ve Zoroğlu, S. (2016). İnternet bağımlılı̆̆ı: Güncel bir gözden geçirme. Journal of Contemporary Medicine, 6(3), 235-247.

Byrne, J. (1999). Health, wealth and honesty: perceptions of self-esteem. Health Education, 99(3), 95-102. 


\section{İ. Bozac1 - Ş. Altın - İ. Gökdeniz 12/2 (2020) 1447-1458}

Chaudhuri, R. H., Mazumdar, S., ve Ghoshal, A. (2011). Conspicuous consumption orientation: Conceptualisation, scale development and validation. Journal of Consumer Behaviour, 10(4), 216-224.

Chung, E., ve Fischer, E. (2001). When conspicuous consumption becomes inconspicuous: the case of the migrant Hong Kong consumers. Journal of Consumer Marketing, 18(6), 474-487.

D'Astous, A. (1990). An Inquiry into the Compulsive Side of Normal Consumers. Journal of Consumer Policy, $13,15-31$.

De Jans, S., Hudders, L., ve Cauberghe, V. (2018). Adolescents' self-reported level of dispositional advertising literacy: how do adolescents resist advertising in the current commercial media environment?. Young Consumers, 19(4), 402-420.

Defever, C., Pandelaere, M. ve Roe, K. (2011). Inducing value-congruent behaviour through advertising and the moderating role of attitude toward advertising. Journal of Advertising, 40(2), 25- 37.

Dittmar H., Long K., Bond R. (2007). When a better self is only a button click away: associations between materialistic values, emotional and identity-related buying motives, and compul $\neg$ sive buying tendency online. Journal of Social and Clinical Psychology, 26(3), 334- 361.

Dittmar, H. (2005). A new look at compulsive buying: Self-discrepancies and materialistic values as predictors of compulsive buying tendency. Journal of Social and Clinical Psychology, 24, 806-833.

Dittmar, H., Long, K., ve Bond, R. (2007). When a better self is only a button click away: Associations between materialistic values, emotional and identity-related buying motives, and compulsive buying tendency online. Journal of social and clinical psychology, 26(3), 334-361.

Durmuş, İ., ve Battal, F. (2018). Üniversite Öğrencilerinin Hazır Giyim Satınalma Kararlarında Reklamlara Yönelik Tutumları Ve Marka Tercihleri. Gümüşhane Üniversitesi Sosyal Bilimler Enstitüsü Elektronik Dergisi, 9(24), 147-176.

Duroy, D., Gorse, P., ve Lejoyeux, M. (2014). Characteristics of online compulsive buying in Parisian students. Addictive behaviors, 39(12), 1827-1830.

Eroğlu, F. (2016). Kompulsif satın alma: Kişisel faktörler, postmodern tüketim şekilleri ve reklama karşı tutumun rolüne yönelik bir araştırma. Balıkesir Üniversitesi Sosyal Bilimler Enstitüsü Dergisi, 19(35), 253282.

Ertemel, A. V., ve Aydın, G. (2018). Dijital ekonomide teknoloji bağımlılığı ve çözüm önerileri, Addicta: Turkish Journal on Addictions, 5(4), 665-690.

Faber, R. J. (1992). Money Changes Everything: Compulsive Buying from Biopsychosocial Perspective. American Behavioral Scientist, 35 (6), 809-819.

Felsher, J., Derevensky, J., ve Gupta, R. (2004). Lottery participation by youth with gambling problems: Are lottery tickets a gateway to other gambling venues?. International Gambling Studies, 4(2), 109-125.

Ferle, C. L., ve Lee, W. N. (2003). Attitudes toward advertising: A comparative study of consumers in China, Taiwan, South Korea and the United States. Journal of International Consumer Marketing, 15(2), 5-23.

Füsun, E. K. Ş. İ., ve Ümmet, D. (2013). Bir kişilerarası iletişim problemi olarak internet bağımlılı̆̆ı ve siber zorbalık: Psikolojik danışma açısından değerlendirilmesi. Değerler Eğitimi Dergisi, 11(25), 91-115.

Gökçearslan, Ş., ve Günbatar, M. S. (2012). Ortaöğrenim Öğrencilerinde İnternet Bağımlılığı. Eğitim Teknolojisi Kuram ve Uygulama, 2(2), 10-24.

Griffiths, M., ve Wood, R. (2001). The psychology of lottery gambling. International gambling studies, 1(1), 2745.

Guo, Z. ve Cai, Y. (2011). Exploring the Antecedents of Compulsive Buying Tendency Among Adolescents in China and Thailand: A Consumer Socialization Perspective. African Journal of Business Management, 5 (24), 10198-10209. 


\section{İ. Bozac1 - Ş. Altın - İ. Gökdeniz 12/2 (2020) 1447-1458}

Günüç, S., ve Kayri, M. (2010). Türkiye'de internet bağımlılık profili ve internet bağımlılık ölçeğinin geliştirilmesi: Geçerlik-güvenirlik çalışması. Hacettepe Üniversitesi Ĕ̆itim Fakültesi Dergisi, 39(39), 220232.

Gürbüz, Sait. (2019), Amos İle Yapısal Eşitlik Modellemesi, Ankara: Seçkin Yayıncılık.

Hair, J. F., Black W. C., Babin B.. J., ve Anderson, R.E. (2009), Multivariate Data Analysis. Seventh Edition.

Hız, G. (2011). Gösterişçi Tüketim Eğilimi Üzerine Bir Alan Araştırması (Muğla Örneği). Organizasyon ve Yönetim Bilimleri Dergisi, 3(2), 117-128.

http://www.tuik.gov.tr/PreTablo.do?alt_id=1028, 16.5.2020.

Hudders, L., Cauberghe, V., ve Panic, K. (2016). How advertising literacy training affect children's responses to television commercials versus advergames. International Journal of Advertising, 35(6), 909-931.

Kalaycı, Şeref. (2009), SPSS Uygulamalı Çok Değişkenli İstatistik Teknikleri, 4. Baskı, Ankara: Asil Yayın.

Khoshghadam, L., Mahdavipour, M. ve Norouzi, K. (2018). Advertising for Symbolic Consumption: Exploring the Moderating Effects of Social Inequality in Formation of Attitude Toward the Ad, 2018 AMA Proceedings, E6E7.

Kim, J.K., Seo, S.H., (2017). An exploration of advertising avoidance by audiences across media. International Journal of Contents, 13, 76-85.

Kocak, P. G. (2017). Gösterişçi Tüketim Üzerine Teorik ve uygulamalı Bir Çalışma: Pamukkale Üniversitesi Örneği. Erciyes Üniversitesi Sosyal Bilimler Enstitüsü Dergisi, 31(43), 79-112. 92.

Kukar-Kinney, M., Ridgway, N. M., ve Monroe, K. B. (2012). The role of price in the behavior and purchase decisions of compulsive buyers. Journal of Retailing, 88(1), 63-71.

Kukar-Kinney, M., Scheinbaum, A. C., ve Schaefers, T. (2016). Compulsive buying in online daily deal settings: An investigation of motivations and contextual elements. Journal of business research, 69(2), 691-699.

Kukar-Kinney, M., Ridgway, N. M., ve Monroe, K. B. (2009). The relationship between consumers' tendencies to buy compulsively and their motivations to shop and buy on the Internet. Journal of Retailing, 85(3), 298-307.

Lapierre, M. A. (2019). Advertising literacy and executive function: Testing their influence on children's consumer behavior. Media Psychology, 22(1), 39-59.

LaRose R, ve Eastin MS. (2002). Is online buying out of control? Electronic commerce and consumer selfregulation. Journal of Broadcasting \& Electronic Media, 46(4), 549-564.

Lee, S.-H., Sharron J. L., ve Nancy A. R. (2000). Compulsive Consumption Tendencies among Television Shoppers. Family and Consumer Sciences Research Journal, 28 (4), 463-88.

Lee, S., Park, J., ve Bryan L. S. (2016). The interplay of Internet addiction and compulsive shopping behaviors. Social Behavior and Personality: an international journal, 44(11), 1901-1912.

Lee, Y. G., Byon, K. K., Ammon, R., ve Park, S. B. R. (2016). Golf product advertising value, attitude toward advertising and brand, and purchase intention. Social Behavior and Personality: an international journal, 44(5), 785-800.

Lee, Y. J., ve Park, J. (2008). The mediating role of consumer conformity in e-compulsive buying. Advances in Consumer Research, 35, 387-392.

Lejoyeux, M., Mathieu, K., Embouazza, H., Huet, F., ve Lequen, V. (2007). Prevalence of compulsive buying among customers of a Parisian general store. Comprehensive Psychiatry, 48(1), 42-46.

MacKenzie, S. B., Lutz, R. J., ve Belch, G. E. (1986). The role of attitude toward the ad as a mediator of advertising effectiveness: A test of competing explanations. Journal of Marketing Research, 23, 130-143.

McElroy, S. L., Keck, P. E., Jr., Pope, H. G., Jr., Smith, J. M., ve Strakowski, S. M. (1994). Compulsive buying: A report of 20 cases. Journal of Clinical Psychiatry, 55(6), 242-248. 


\section{İ. Bozac1 - Ş. Altın - İ. Gökdeniz 12/2 (2020) 1447-1458}

Melnikas, B., ve Smaliukiene, R. (2007). Consumer vulnerability in pharmaceutical market: Case of Baltic countries. Journal of Business Economics and Management, 8(1), 51-62.

Meydan, C. H., ve Şeşen, H. (2015). Yapısal Eşitlik Modellemesi-Amos Uygulamaları, İkinci Baskı, İstanbul: Detay Yayıncilik,

Moore, D. J., ve Lee, S. P. (2012). How advertising influences consumption impulses. Journal of Advertising, 41(3), 107-120.

Müller, A., ve Mitchell, J. E. (2014). Internet shopping from a psychiatric perspective. Psychiatric Annals, 44(8), 384-387.

O'Guinn, T. C., ve Faber, R. J. (1989). Compulsive buying: A phenomenological exploration. Journal of Consumer Research, 16(2), 147-157.

Pechmann, C., Levine, L., Loughlin, S., ve Leslie, F. (2005). Impulsive and self-conscious: Adolescents' vulnerability to advertising and promotion. Journal of Public Policy \& Marketing, 24(2), 202-221.

Podoshen, J. S., Andrzejewski, S. A., ve Hunt, J. M. (2014). Materialism, conspicuous consumption, and American hip-hop subculture. Journal of International Consumer Marketing, 26(4), 271-283.

Prendergast, G., Cheung, W. L., ve West, D. (2010). Antecedents to advertising avoidance in China. Journal of Current Issues \& Research in Advertising, 32(2), 87-100.

Redondo, I., ve Aznar, G. (2018). To use or not to use ad blockers? The roles of knowledge of ad blockers and attitude toward online advertising. Telematics and Informatics, 35(6), 1607-1616.

Schumacker, R. E. ve Lomax, R. G. (2010). A Beginner's Guide To Structural Equation Modeling. Third Edition.

Segal, B., ve Podoshen, J. S. (2013). An examination of materialism, conspicuous consumption and gender differences. International Journal of Consumer Studies, 37(2), 189-198.

Sharma, P., Sivakumaran, B., ve Marshall, R. (2010). Impulse buying and variety seeking: A traitcorrelates perspective. Journal of Business Research, 63, 276-283.

Sohn, S. ve Choi, Y. (2012). A Model of Compulsive Buying: Dysfunctional Beliefs and Self-Regulation of Compulsive Buyers. Social Behaviour and Personality, 40 (10), 1611-1624.

Şimşek, Ö. F. (2007). Yapısal Eşitlik Modellemesine Giriş-Temel Illkeler ve Lisrel Uygulamaları. Ankara: Ekinoks.

Tabachnick, B. G., ve Fidell, L. S. (2012). Using Multivariate Statistics. Sixth Edition, USA: Pearson.

Tan, S.J., ve Chia, L. (2007). Are we measuring the same attitude? Understanding media effects on attitude towards advertising. Marketing Theory, 7(4), 353-77.

Thrift, N. (2008). The material practices of glamour. Journal of Cultural Economy, 1, 9-23.

Vanwesenbeeck, I., Ponnet, K., ve Walrave, M. (2017). Young adolescents' advertising literacy and purchase intention in social network games: Influence of perspective taking and need for cognition. Journal of Consumer Behaviour, 16(1), 23-33.

Wang C. C., ve Yang H.W.(2008). Passion for online shopping: the influence of personality and compul $\neg$ sive buying. Social Behavior and Personality, 36(5), 693-706.

Wolin, L. D., Korgaonkar, P. ve Lund, D. (2002). Beliefs, Attitudes and Behaviour Towards: Web Advertising. International Journal of Advertising: The Review of Marketing Communications, 21(1), 87-113.

Yılmaz, E., Şahin, Y. L., Haseski, H. İ., ve Erol, O. (2014). Lise öğrencilerinin internet bağımlılık düzeylerinin çeşitli değişkenlere göre incelenmesi: Balıkesir ili örneği. Eğitim Bilimleri Araştırmaları Dergisi, 4(1), 133144.

Yoon, K. (1995). Comparison of beliefs about advertising, attitude toward advertising, and materialism held by African Americans and Caucasians. Psychological Reports, 77, 455-466. 